\title{
Copper Removal from Electroplating Wastewater by Coprecipitation of Copper-Based Supramolecular Materials: Preparation and Application Study
}

\author{
De-Kui Bai,, ${ }^{1,2}$ Quan-Hong Ying, ${ }^{2}$ Ni Wang, ${ }^{2}$ and Jin-Hui Lin ${ }^{1}$ \\ ${ }^{1}$ College of Materials and Chemistry and Chemical Engineering, Chengdu University of Technology, Chengdu 610059, China \\ ${ }^{2}$ Mianyang Product Quality Supervision and Inspection Institute, Mianyang 621000, China \\ Correspondence should be addressed to De-Kui Bai; bdk123123@126.com
}

Received 16 November 2015; Revised 17 January 2016; Accepted 14 February 2016

Academic Editor: Ewa Schab-Balcerzak

Copyright (C) 2016 De-Kui Bai et al. This is an open access article distributed under the Creative Commons Attribution License, which permits unrestricted use, distribution, and reproduction in any medium, provided the original work is properly cited.

This paper describes an experimental study for the removal of copper ions from electroplating wastewater. Different metal ions are added to the wastewater to remove copper ions by coprecipitation and the copper-based supramolecular materials with layered structures are obtained. It is found that the best results are obtained with the addition of $-\mathrm{Mg}^{2+}-\mathrm{Al}^{3+}$ mixture with ratio of $3: 1, \mathrm{pH}$ $\approx 10$, and aging for $1 \mathrm{~d}$ at $60^{\circ} \mathrm{C}$. With these conditions, the residual copper in the electroplating wastewater satisfies national emission standards and wastewater handling capacity of up to $30 \mathrm{~mL}$ can be achieved. The properties of the copper-based supramolecular materials prepared under these optimal conditions are characterized. The results show that the materials have a layered structure and good thermal and structural stability and achieve a saturated adsorption of iodide ions of $41.23 \mathrm{mg} / \mathrm{g}$.

\section{Introduction}

Electroless plating of metal coatings onto nonmetallic surfaces by means of chemical deposition can provide protection and improve the performance of the plated surface in various technical applications [1-3]. The coating produced by electroless copper plating exhibits excellent adhesion, corrosion resistance, reliability, heat resistance, and electromagnetic shielding, and the process has the advantage of producing an even coating. In addition, the chemical plating technique is applicable to the treatment of surfaces that are not electrically conducting [4-6].

Both the electroplating process itself and the cleaning of the coating produce a considerable amount of waste. In particular, electroplating wastewater contains a wide range of copper compounds, in addition to $\mathrm{Fe}^{3+}, \mathrm{Zn}^{2+}, \mathrm{Cd}^{2+}$, $\mathrm{Ni}^{2+}, \mathrm{Cr}^{3+}$, and many other heavy metal ions. Not only do these represent a waste of resources, but as environmental pollutants they are hazardous to human and animal health [7-9]. But from the development of electroplating wastewater treatment technology in recent decades, $80 \%$ of electroplating wastewater is using chemical methods to deal with the copper in electroplating wastewater at home and on-abroad. In addition, electrolysis, ion exchange, adsorption, and membrane separation method are used. Contemporary copper is widely used, and many kinds of copper-containing wastewater are produced. According to the nature of electroplating waste water and concentration of copper in wastewater, the different methods of removal of copper in wastewater have been applied. The high copper concentration electroplating waste water dealt with neutralization and electrolysis, while the low copper concentration electroplating waste water can use the restore method or methods to mix. Copper is an essential trace element in the diet, but excessive intake can have toxic effects. For copper electroplating enterprises, the emission limit specified in the Chinese national standards is $\leqslant 0.5 \mathrm{mg} / \mathrm{L}$ [10].

Supramolecular materials are based on supramolecular chemistry, which has had wide applications in a number of areas of materials science and technology [11-14]. In recent 
years, there has been great progress in the use of supramolecular materials in molecular devices and as liquid crystals, biomaterials, and nanomaterials [15-18].

In the study reported here, copper in electroplating wastewater is removed by a coprecipitation method by which copper-based supramolecular materials with layered structures are formed. The method was used in electroplating wastewater by adding a certain concentration of metal ions (such as $\mathrm{Mg}^{2+}, \mathrm{Al}^{3+}$ ); then layered double hydroxides (LDHs) formed by reaction between added metal ions and $\mathrm{Cu}^{2+}$ in waste in which board consists of liquid waste of copper ions and metal ions plus. Content of copper ion from waste was reduced and simultaneously the layered material formatted which structure between the layers is made up of calcium carbonate and hydroxyl anion. After high temperature roasting, losing structure interlayer anions and structure layer board of hydroxyl reserves layer board structure. So the layered structure material has strong adsorption for anion. The preparation and properties of these materials are investigated with regard to the use of this method in environmental protection.

\section{Experimental}

2.1. Instruments and Reagents. An inductively coupled plasma optical emission spectrometer (ICP-OES710ES, Varian), a constant-temperature electric drying oven (DHG9101.1SA), an electronic analytical balance (Sartorius), and an atomic absorption spectrometer (AA7000) were used.

The reagents used were $\mathrm{Mg}\left(\mathrm{NO}_{3}\right)_{2} \cdot 6 \mathrm{H}_{2} \mathrm{O}$, $\mathrm{Al}\left(\mathrm{NO}_{3}\right)_{3} \cdot 9 \mathrm{H}_{2} \mathrm{O}, \quad \mathrm{Na}_{2} \mathrm{CO}_{3}, \mathrm{NaOH}, \mathrm{CuCl}_{2} \cdot 2 \mathrm{H}_{2} \mathrm{O}, \mathrm{HCl}$, $\mathrm{Ca}\left(\mathrm{NO}_{3}\right)_{2} \cdot 4 \mathrm{H}_{2} \mathrm{O}, \mathrm{FeSO}_{4} \cdot 7 \mathrm{H}_{2} \mathrm{O}, \mathrm{ZnSO}_{4} \cdot 7 \mathrm{H}_{2} \mathrm{O}, \mathrm{KI}, \mathrm{H}_{3} \mathrm{PO}_{4}$, $\mathrm{HCOOH}$, and $\mathrm{Br}_{2}$. All were analytically pure.

2.2. Electroplating Wastewater Composition. The copper electroplating wastewater used in the experiment was provided by the manufacturer and the stock solution was diluted 20 times. Determination of the metal content of the wastewater by ICP-OES revealed that the concentrations of $\mathrm{Cu}$ were $8.8 \mathrm{~g} / \mathrm{L}$, as shown in Table 1 together with the concentrations of the other main elements present.

\subsection{Experimental Procedure}

2.3.1. Determination of Residual Copper Content of Wastewater. The copper content was determined by flame atomic absorption spectrometry (AAS) with the instrument parameters shown in Table 2.

\subsubsection{Coprecipitation Method for Removal of Copper from} Wastewater. A standard procedure was used for the preparation of copper-based supramolecular materials. Firstly, $0.13 \mathrm{~mol} / \mathrm{L} \mathrm{Al}\left(\mathrm{NO}_{3}\right)_{3}$ and $0.40 \mathrm{~mol} / \mathrm{L} \mathrm{Mg}\left(\mathrm{NO}_{3}\right)_{2}$ were prepared in a $100 \mathrm{~mL}$ beaker. Afterwards, $15 \mathrm{~mL}$ electroplating wastewater and $30 \mathrm{~mL}$ deionized water were added. The mixture was transferred to a constant-voltage funnel and slowly dripped into an aqueous solution of $\mathrm{Na}_{2} \mathrm{CO}_{3}(0.25 \mathrm{~mol} / \mathrm{L}$, $90 \mathrm{~mL})$ under constant stirring. $\mathrm{NaOH}(0.1 \mathrm{~mol} / \mathrm{L})$ was then added to adjust the $\mathrm{pH}$ to 10 . The resulting mixture was stirred
TABLE 1: Main element content of electroplating wastewater.

\begin{tabular}{lccccccccccc}
\hline Element & $\mathrm{Na}$ & $\mathrm{K}$ & $\mathrm{Ca}$ & $\mathrm{Mg}$ & $\mathrm{Al}$ & $\mathrm{Fe}$ & $\mathrm{Cr}$ & $\mathrm{Zn}$ & $\mathrm{Cu}$ & $\mathrm{Ni}$ & $\mathrm{Cd}$ \\
\hline $\begin{array}{l}\text { Content } \\
(\mathrm{g} / \mathrm{L})\end{array}$ & 0.36 & 0.36 & 0.25 & 0.05 & 0.86 & 0.23 & 0.06 & 8.4 & 8.8 & 11.3 & 29.9 \\
\hline
\end{tabular}

for 30 minutes and left to aging for $1 \mathrm{~d}$ at $60^{\circ} \mathrm{C}$. The copper content in the supernatant was determined by AAS. Finally, the mixture was filtered and the precipitate was washed with distilled water, dried, and roasted for $3 \mathrm{~h}$ at $400^{\circ} \mathrm{C}$ in a muffle furnace.

\subsubsection{Adsorption Determination}

UV-Spectrophotometric Determination of Iodide. $1 \mathrm{~mL}$ solution was sampled and placed in a $50.00 \mathrm{~mL}$ volumetric flask, to which deionized water $(10 \mathrm{~mL})$ and bromine water $(2$ drops) were added, followed by shaking and standing for $5 \mathrm{~min}$. Formic acid $(1.0 \mathrm{~mL})$ was then added and the mixture was shaken until it was colorless. Phosphate $(2.0 \mathrm{~mL})$ was then added and the mixture was shaken again. Finally, an aqueous solution of KI ( $1 \mathrm{~mL})$ was added, and then the mixture was diluted and shaken. When the reaction was allowed to proceed for $30 \mathrm{~min}$, the absorbance was determined at $350 \mathrm{~nm}$

\section{Results and Discussion}

3.1. Comparison of Removal Rates of Copper from Electroplating Wastewater and Optimization of Experimental Conditions. According to the GB21900-2008 standard concerning the emission of pollutants from electroplating, the copper concentration in electroplating wastewater must not exceed $0.5 \mathrm{mg} / \mathrm{L}$. As described in Section 2.3.1, the residual concentration of the copper in the electroplating wastewater was determined in order to evaluate the effects of different experimental conditions.

3.1.1. Effects of Different Metal Ions on Removal of Copper. According to the Jahn-Teller effect, layered double hydroxides (LDHs) from copper alone are not stable owing to the high copper content in electroplating wastewater, and accordingly, there is less precipitation. In order to increase the total amount of precipitation, other metal ions were required. Figure 1 shows the effect of the addition of different metal ions on the residual concentration of $\mathrm{Cu}^{2+}$ in the supernatant after coprecipitation. The results show that the addition of $\mathrm{Ca}^{2+}, \mathrm{Fe}^{2+}, \mathrm{Zn}^{2+}$, or $\mathrm{Mg}^{2+}-\mathrm{Al}^{3+}$ reduced the concentration of copper ions in the electroplating wastewater. It is clearly observed that the addition of $\mathrm{Mg}^{2+}-\mathrm{Al}^{3+}$ gives the most effective removal of copper with a residual copper concentration of $0.46 \mathrm{mg} / \mathrm{L}$. Such a lower concentration is in conformity with national emission standards.

The total coprecipitate was characterized by X-ray diffraction (XRD), as shown in Figure 2. The coprecipitates that formed with electroplating wastewater, or electroplating wastewater and $\mathrm{Ca}^{2+}, \mathrm{Fe}^{2+}, \mathrm{Zn}^{2+}$, and $\mathrm{Mg}^{2+}$, showed no 
TABLE 2: Instrument parameters for AAS.

\begin{tabular}{lccccc}
\hline Element & $\lambda / \mathrm{nm}$ & Gas & Slit $/ \mathrm{nm}$ & Current/mA & Flame \\
\hline $\mathrm{Cu}$ & 324.75 & Air- $\mathrm{C}_{2} \mathrm{H}_{2}$ & 0.2 & 3.0 & Lean combustion \\
\hline
\end{tabular}

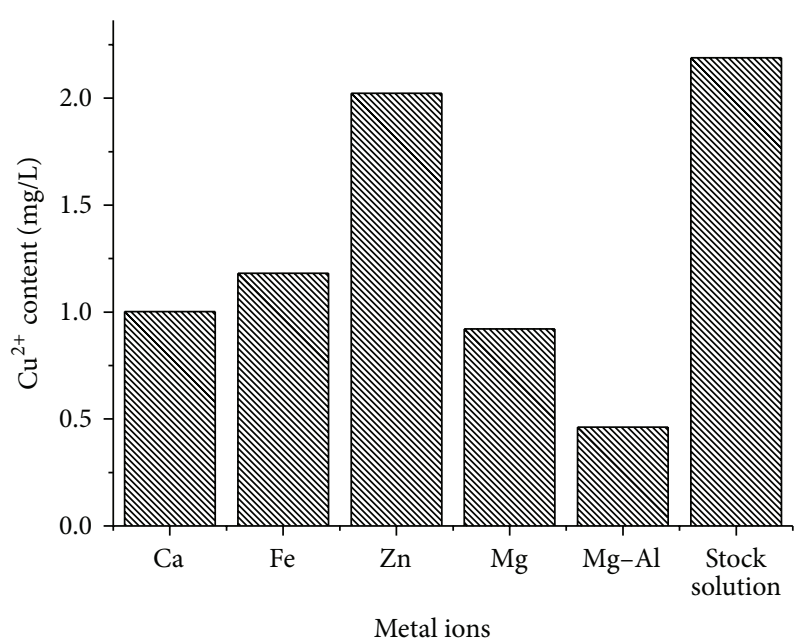

FIGURE 1: Effects of different metal ions on removal of copper.

peculiarities in their XRD peak sand that could be assumed to be ordinary sediments. In contrast, the coprecipitate that formed with electroplating wastewater and $\mathrm{Mg}^{2+}-\mathrm{Al}^{3+}$ showed characteristics representing a typical LDHs stratified structure, with a sharp diffraction peak at low angle $2 \theta$ [19]. In addition, the material absorption peak was in line with the 37-0630 map, matching the characteristics of $\mathrm{Cu}_{6} \mathrm{Al}_{2}(\mathrm{OH}) \cdot 16 \mathrm{CO}_{3} \cdot 4 \mathrm{H}_{2} \mathrm{O}$. These results indicated the formation of copper-containing layered metal hydroxides $(\mathrm{Cu}-$ $\mathrm{Mg}-\mathrm{Al} \mathrm{LDHs}$ ), copper generated cupric hydroxides which constitute the layered structure of supramolecular materials layer board together with magnesium and aluminum. They also show that the addition of $\mathrm{Mg}^{2+}-\mathrm{Al}^{3+}$ provides the best route to copper removal via the formation of supramolecular materials with layered structures.

3.1.2. Effects of $\mathrm{Mg}^{2+} / \mathrm{Al}^{3+}$ Ratio on Removal of Copper. According to the results shown in Figure 3, when the ratio of $\mathrm{Mg}^{2+}$ to $\mathrm{Al}^{3+}$ was increased to $3: 1$, the residual concentration of the copper in the electroplating wastewater was about $0.2 \mathrm{mg} / \mathrm{L}$, in conformity with national emission standards. When the ratio of $\mathrm{Mg}^{2+}$ to $\mathrm{Al}^{3+}$ is $3 / 1$, the lowest copper concentration was observed for the fact that most copper is incorporated into the $\mathrm{LDH}$ layers with the formation of $\mathrm{Cu}-$ $\mathrm{Mg}-\mathrm{Al} \mathrm{LDH}$.

3.1.3. Effects of $p H$ on Removal of Copper. It is found that the increasing $\mathrm{pH}$ can promote the formation of coprecipitation and hence increasing the removal of copper. As shown in Figure 4, the amount removed reached the highest with increasing $\mathrm{pH}$ to 10 , beyond which no significant increase was observed. Therefore, a value of $\mathrm{pH} 10$ is chosen for further study.

3.1.4. Effects of Aging Temperature on Removal of Copper. Two parallel samples (samples 1 and 2) were prepared under the same conditions but with different temperatures (room temperature of $40^{\circ} \mathrm{C}$ or $60^{\circ} \mathrm{C}$ ). The results in Figure 5 show that, compared with aging at room temperature, aging at $60^{\circ} \mathrm{C}$ and aging at $40^{\circ} \mathrm{C}$ led to a greater amount of copper being removed as a result of the more rapid and efficient crystallization of $\mathrm{Cu}-\mathrm{Mg}-\mathrm{Al} \mathrm{LDHs}$ at $60^{\circ} \mathrm{C}$. Thus, the optimal aging temperature is $60^{\circ} \mathrm{C}$.

3.1.5. Effects of Aging Time on Removal of Copper. Again, two parallel samples (samples 1 and 2) were prepared and subjected to aging for different times. The results in Figure 6 show that longer aging leads to better crystallization of the $\mathrm{Cu}-$ $\mathrm{Mg}-\mathrm{Al} \mathrm{LDHs}$. An aging time of $1 \mathrm{~d}$ is enough to assure that residual $\mathrm{Cu}^{2+}$ concentration in the electroplating wastewater is in accordance with the national emission standards.

3.2. Maximum Handling Capacity of Electroplating Wastewater. Wastewater dosages were selected as 5, 15, 25, 35, 45, or $50 \mathrm{~mL}$. As shown in Figure 7, when more than $30 \mathrm{~mL}$ of wastewater was added, the effect of removal of copper was gradually reduced until residual $\mathrm{Cu}^{2+}$ in the wastewater was no longer in accordance with national emission standards. This is a consequence of the layer between the $\mathrm{Cu}-\mathrm{Mg}-\mathrm{Al}$ LDHs becoming saturated with water so that no more copper can be incorporated. Thus, the maximum handling capacity of electroplating wastewater is $30 \mathrm{~mL}$.

\subsection{Material Performance}

3.3.1. Thermal Stability. As shown in Figure 8, the thermogravimetry-differential scanning calorimetry (TG-DTA) graph exhibits three absorption peaks. The first is at $134.4^{\circ} \mathrm{C}$, with a weight loss of 9.70\%; this represents removal of surface adsorption and interlayer water molecules. The second peak is at $352.8^{\circ} \mathrm{C}$, with a weight loss of $15.19 \%$; this probably represents the emergence of interlayer anions. The final peak is $551.7^{\circ} \mathrm{C}$, with a weight loss of $10.52 \%$; this represents dehydroxylation of the layers. The DTA curve has a strong endothermic peak at $354.8^{\circ} \mathrm{C}$. At this temperature, the low-angle diffraction peak in the XRD pattern of the $\mathrm{Cu}-\mathrm{Mg}-\mathrm{Al} \mathrm{LDHs}$ disappears, indicating destruction of the original layered structure.

3.3.2. Structural Stability. As shown in Figure 9, at lower solution $\mathrm{pH}$, there is greater desorption of copper from the copper-based supramolecular material as a result of delamination. However, the amount of copper released into the solution is still in conformity with national emission standards. 


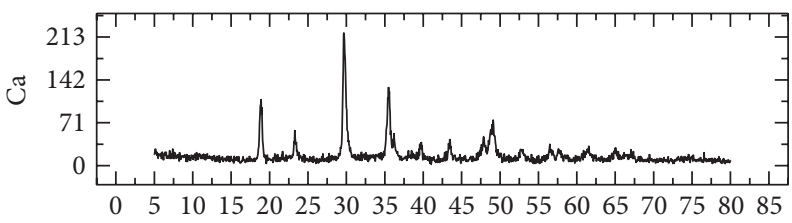

$-\mathrm{Ca}$

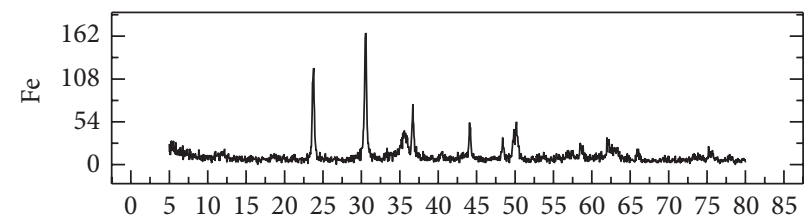

A

$-\mathrm{Fe}$

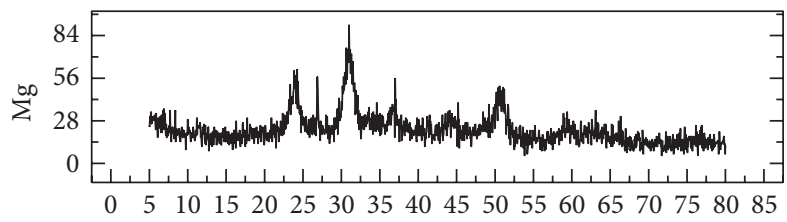

A

$-\mathrm{Mg}$

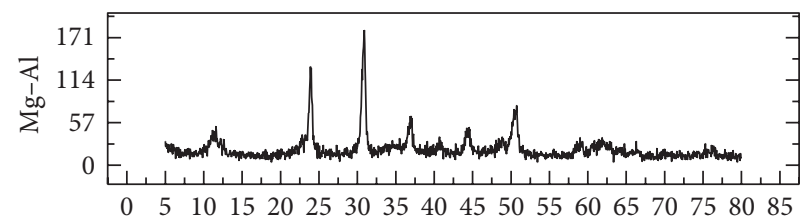

A

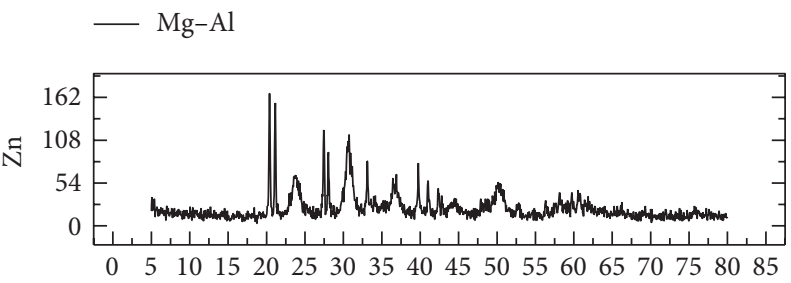

A

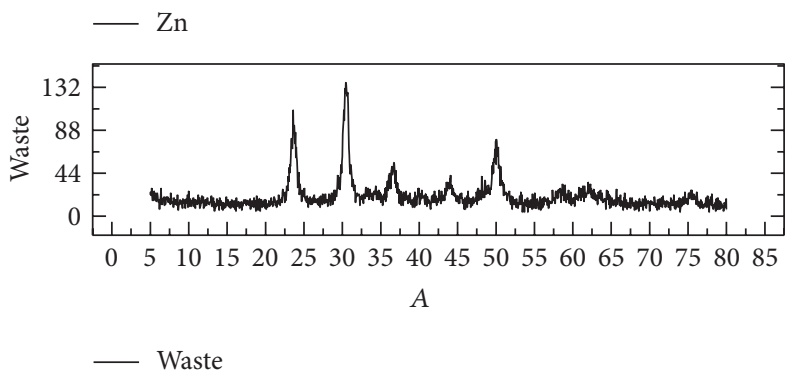

FIGURE 2: XRD patterns of copper-based metal-containing LDH materials.

At a solution $\mathrm{pH}$ close to neutral, hardly any copper is released. The result shows that $\mathrm{Cu}-\mathrm{Mg}-\mathrm{Al} \mathrm{LDH}$ exhibit strong structural stability and there is little risk of desorption causing secondary pollution.
3.3.3. Adsorption Capacity to Iodide. For adsorption testing, $\mathrm{Cu}-\mathrm{Mg}-\mathrm{Al} \mathrm{LDH}$ material was dried, roasted for $3 \mathrm{~h}$ at $400^{\circ} \mathrm{C}$ in a muffle furnace, and then ground to powder. Samples of $0.1 \mathrm{~g} \mathrm{Cu}-\mathrm{Mg}-\mathrm{Al} \mathrm{LDH}$ were placed in a $50 \mathrm{~mL}$ Erlenmeyer 


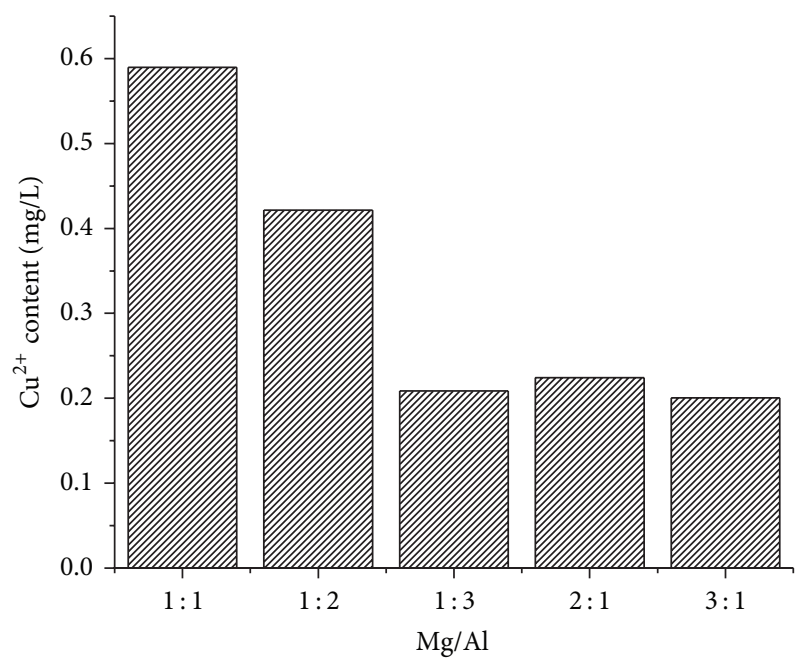

FIGURE 3: Effect of magnesia-alumina molar ratio on removal of copper.

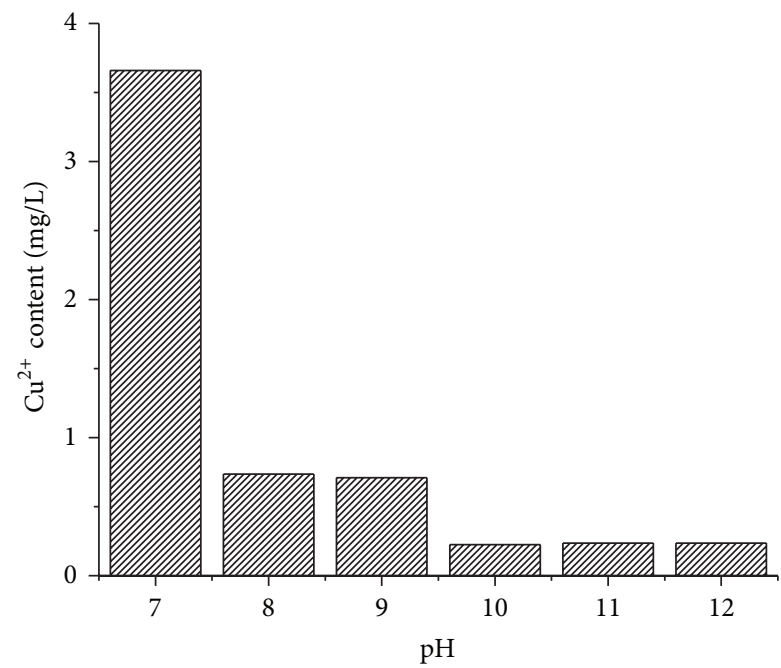

FIGURE 4: Effect of $\mathrm{pH}$ on removal of copper.

flask together with $25.00 \mathrm{~mL}$ of different concentrations of iodide solution and the mixture was shaken for $1 \mathrm{~h}$ at $35^{\circ} \mathrm{C}$. The remaining iodide ion concentration in the solution was then determined as described in Section 2.3.3 and the adsorption ratio was calculated. As shown in Figure 10, with increasing $\mathrm{I}^{-}$concentration in the initial solution, the adsorption capacity gradually increases. For an initial $\mathrm{I}^{-}$ concentration of $800 \mathrm{mg} / \mathrm{L}$, the adsorption equilibrium was achieved and adsorption capacity was $41.23 \mathrm{mg} / \mathrm{g}$. $\mathrm{Cu}-\mathrm{Mg}-\mathrm{Al}$ LDHs showed good adsorption properties for $\mathrm{I}^{-}$, which could be explained by penetration of $\mathrm{I}^{-}$into the layered structure of the $\mathrm{Cu}-\mathrm{Mg}-\mathrm{Al} \mathrm{LDH}$ and also by the occurrence of a specific redox reaction between $\mathrm{Cu}$ in the $\mathrm{Cu}-\mathrm{Mg}-\mathrm{Al} \mathrm{LDHs}$ and $\mathrm{I}^{-}$, producing $\mathrm{CuI}$ and indirectly enhancing the adsorption capacity for $\mathrm{I}^{-}$.

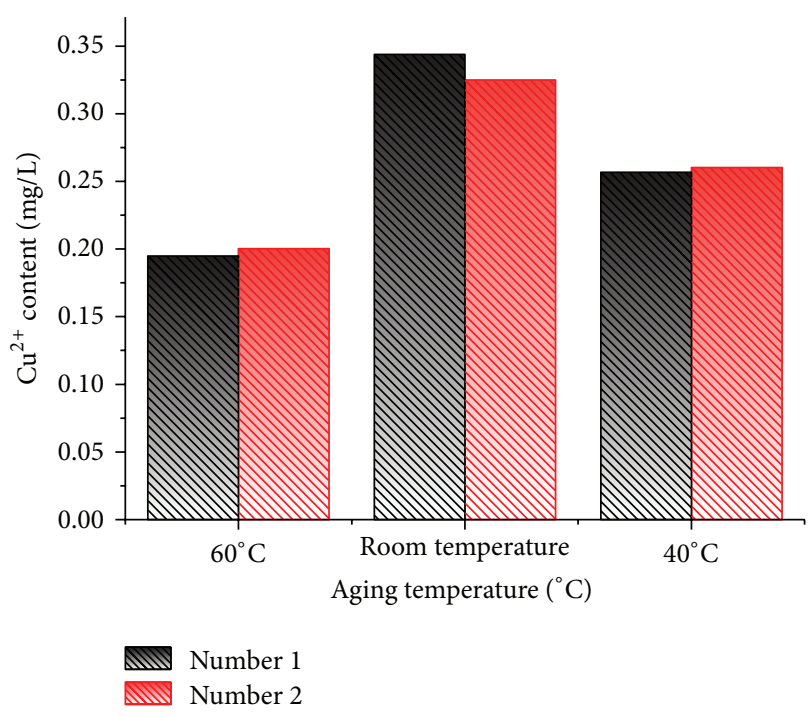

FIGURE 5: Effect of aging temperature on removal of copper.

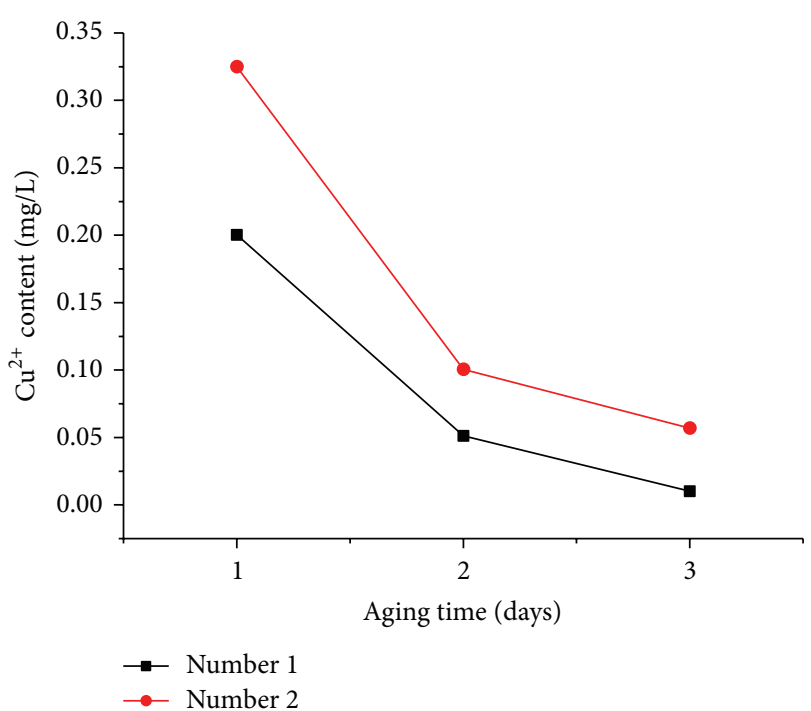

Figure 6: Effect of aging time on removal of copper.

\section{Conclusion}

This study reveals that $\mathrm{Mg}^{2+}-\mathrm{Al}^{3+}$ coprecipitation is effective at reducing the content of copper in electroplating wastewater so that the residual copper is in conformity with national emission standards. The copper is removed as $\mathrm{Cu}-\mathrm{Mg}-\mathrm{Al}$ LDHs formed by reaction between $\mathrm{Mg}^{2+}-\mathrm{Al}^{3+}$ and $\mathrm{Cu}^{2+}$. The $\mathrm{Cu}-\mathrm{Mg}-\mathrm{Al} \mathrm{LDHs}$ have typical layered structures, good thermal and structural stability, and good adsorption capacity for $\mathrm{I}^{-}$. The results of this study are significant for environmental pollution control applications, and further investigations will consider whether the method can be applied to other inorganic metal ions and to the treatment of organic liquid wastes. 


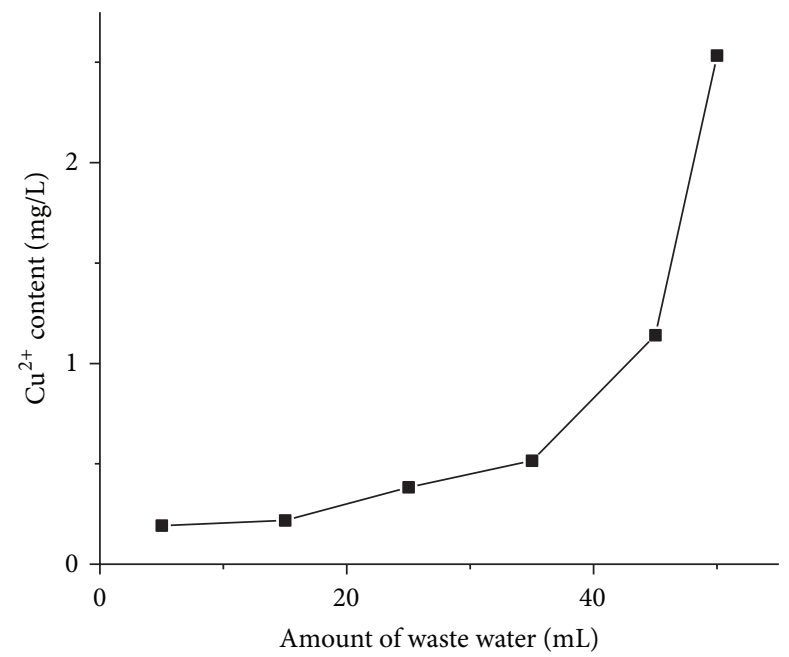

FIgURE 7: Maximum treatment of electroplating wastewater containing copper.

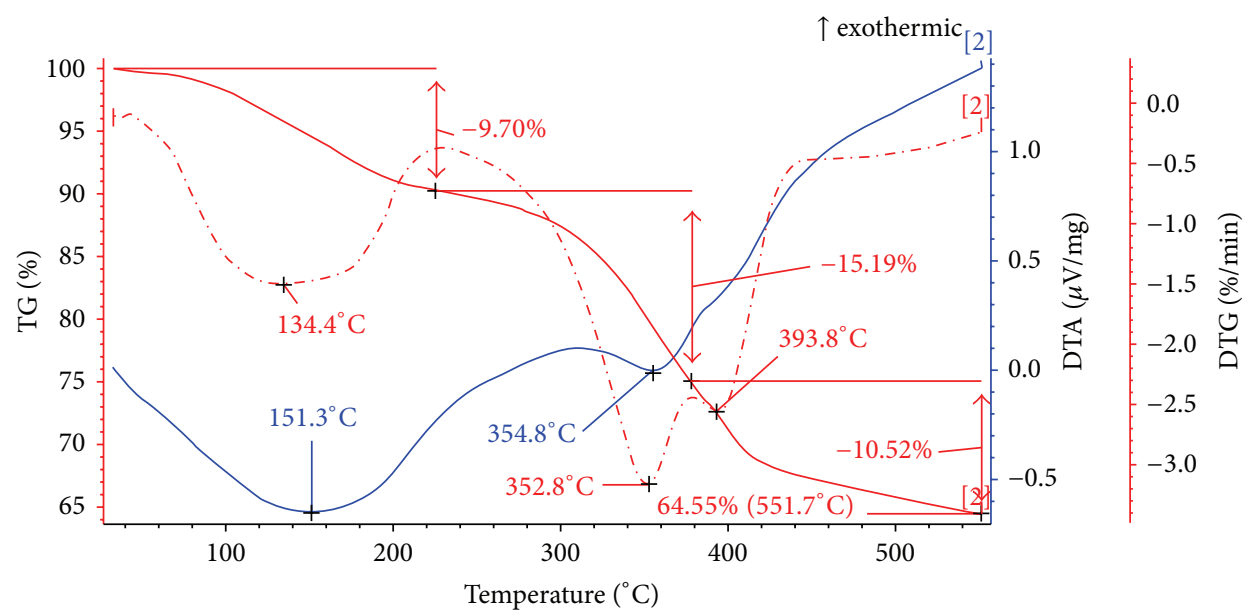

[2] Mg-Al-(2) 15K-AR. dsv

- TG

- DTA

FIGURE 8: TG-DTA curve of copper-based supramolecular materials.

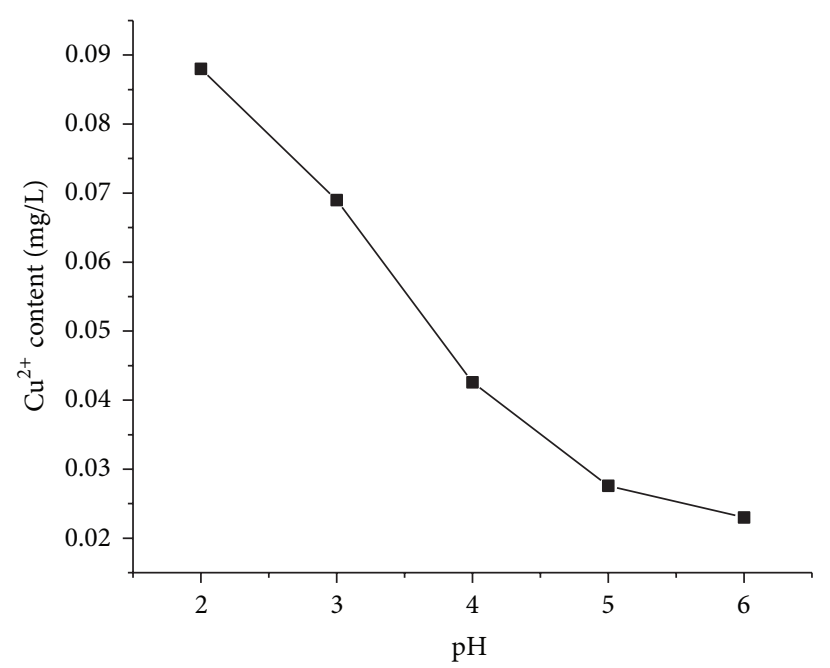

FIGURE 9: Desorption curve of copper in copper-based supramolecular materials. 


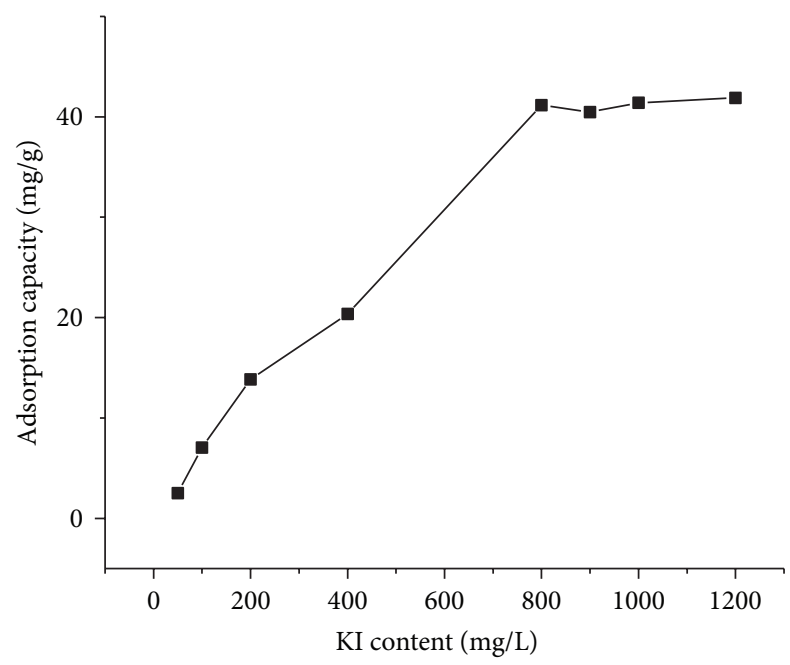

FIGURE 10: Iodide adsorption capacity of $\mathrm{Cu}-\mathrm{Mg}-\mathrm{Al} \mathrm{LDH}$ material as a function of initial iodide content.

\section{Conflict of Interests}

The authors declare that there is no conflict of interests regarding the publication of this paper.

\section{Acknowledgment}

This work was financially supported by the Science and Technology Department of Sichuan Province (no. 2015GZ0243).

\section{References}

[1] C. Guofeng, L. Ning, and L. Deyu, "Applications and prospects of electroless Cu plating in microelectronic field," Electroplating Pollution Control, vol. 23, no. 5, pp. 5-6, 2003.

[2] A. Vaškelis, E. Norkus, and J. Jačiauskienè, "Kinetics of electroless copper deposition using cobalt(II)-ethylenediamine complex compounds as reducing agents," Journal of Applied Electrochemistry, vol. 32, no. 3, pp. 297-303, 2002.

[3] R. Huang, "The development trend of electroplating wastewater treatment in 21st century," Plating and Finishing, vol. 22, no. 3, pp. 1-2, 2000.

[4] Z. Yang, L. Zhu, and Y. Chen, Modern Environmental Geochemistry, Geology Publishing House, Beijing, China, 1999.

[5] S. Lifen, Y. Yujie, Y. Shuguang et al., "Copper electroplating wastewater treatment technology is reviewed," Industrial Water and Wastewater, vol. 38, no. 3, pp. 13-17, 2007.

[6] Q. Wang, B. Huang, X. Zhang, and F. Li, "Study on recovering copper by electrowinning method from concentrated effluent containing cyanide solution," Research of Environmental Sciences, vol. 11, no. 6, pp. 30-33, 1998.

[7] M. Xiang and H. Guofei, Heavy Metal Wastewater Treatment, Chemical Industry Press, Beijing, China, 2000.

[8] O. A. Hougen, "Seven Decades of Chemical Engineering," Chemical Engineering Progress, vol. 73, no. 1, pp. 89-104, 1977.

[9] L. E. Scriven, "The role of past, current, and future technologies in chemical engineering," Chemical Engineering Progress, no. 12, pp. 65-69, 1987.
[10] Ministry of Environmental Protection of the People's Republic of China, "Emission standard of pollutants for electroplating," GB 21900-2008, 2008.

[11] Z. Chengfei, Q. Zongneng, and Y. Yilun, "Supramolecular materials technology," Journal of Biomedical Engineering, vol. 2, no. 4, article 240, 1985.

[12] D.-Y. Yan, Y.-F. Zhou, and J. You, "Supramolecular self-assembly of macroscopic tubes," Science, vol. 303, no. 5654, pp. 65-67, 2004.

[13] S.-L. Xiao, X. Du, L. Qin, C.-H. He, and G.-H. Cui, "Synthesis, crystal structures and fluorescence properties of two onedimensional cadmium(II) coordination polymerscontaining flexible bis(benzimidazole) ligands," Journal of Inorganic and Organometallic Polymers and Materials, vol. 22, no. 6, pp. 13841390, 2012.

[14] D. Xue and Z. Fazhi, Layer Assembly and Functional Materials, Chemical Industry Press, Beijing, China, 2007.

[15] L. Liang, Adsorption and ion-exchange behavior of layered double hydroxides in the uptake of halide anions from aqueous solution [Dissertation], Beijing University of Chemical Technology, Beijing, China, 2005.

[16] Z. Kong, C. Wang, Y. Ren et al., "Synthesis, structure, and properties of two supramolecular compounds based on silicotungstic acid and transition metal(II) coordinated isonicotinic acid," Chinese Journal of Chemistry, vol. 30, no. 4, pp. 759-764, 2012.

[17] Z. Jiang, Z. Hao, J. Yu, H. Hou, C. Hu, and J. Su, "Catalytic combustion of methane on novel catalysts derived from $\mathrm{Cu}$ Mg/Al-hydrotalcites," Catalysis Letters, vol. 99, no. 3-4, pp. 157163, 2005.

[18] J. Yang, F. Chen, Y. Ye, Z. Fei, and M. Zhong, "Preparation and characterization of polystyrene (PS)/layered double hydroxides (LDHs) composite by a heterocoagulation method," Colloid and Polymer Science, vol. 288, no. 7, pp. 761-767, 2010.

[19] X.-Q. Jiang, H.-Z. Wang, and P.-C. Deng, "Adsorption behavior of Mg-Al layered double-hydroxides to I-," Journal of Salt amd Chemical Industry, no. 5, pp. 1-2, 2006 (Chinese). 

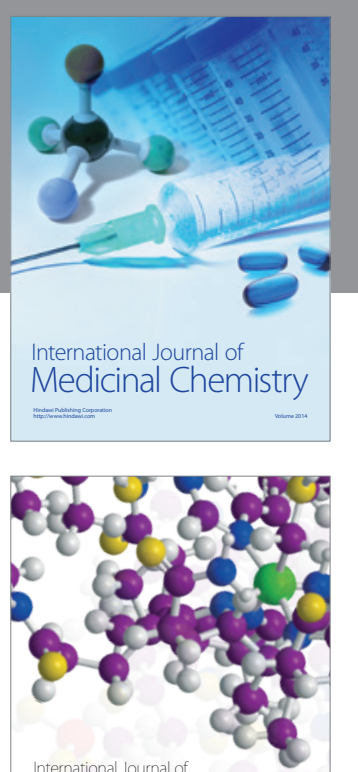

Carbohydrate Chemistry

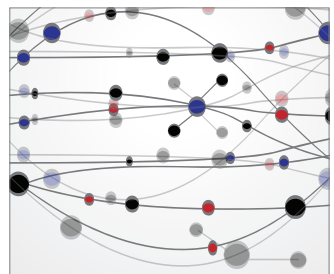

The Scientific World Journal
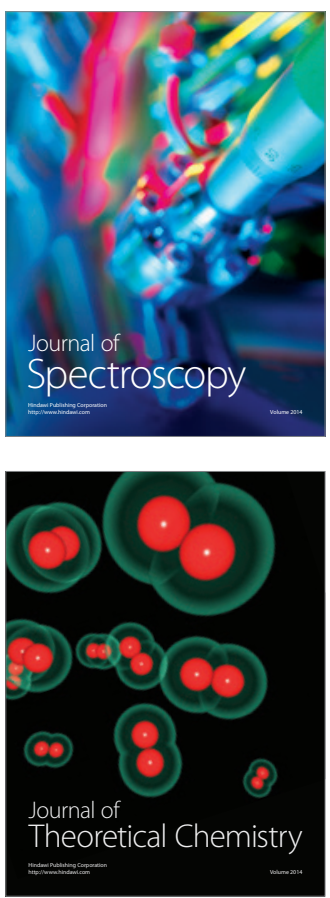
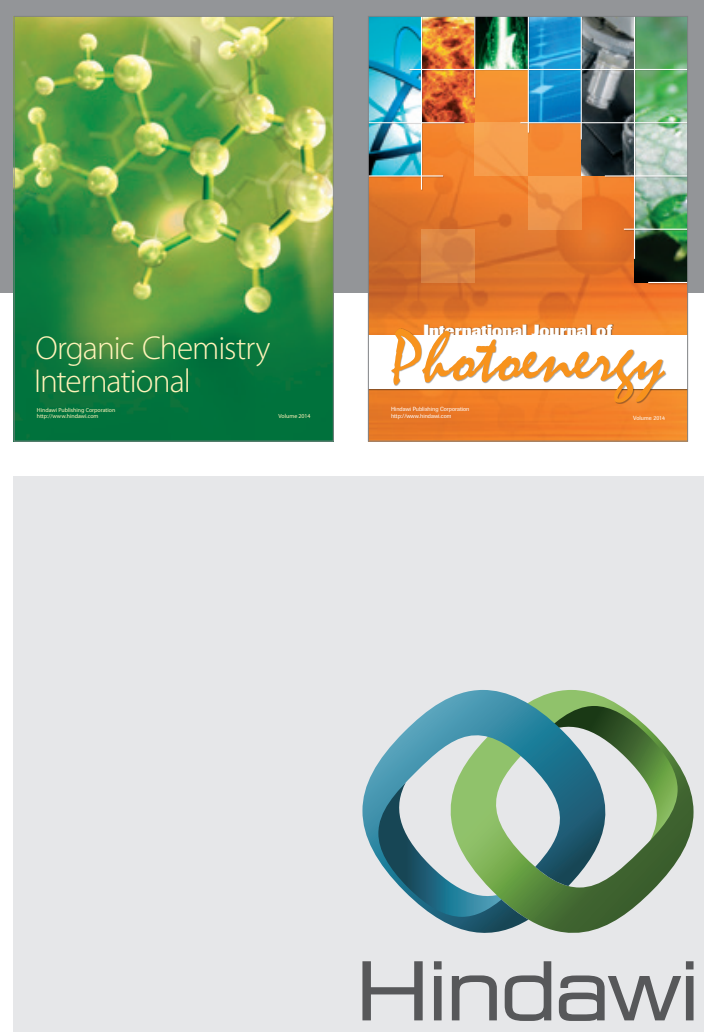

Submit your manuscripts at

http://www.hindawi.com

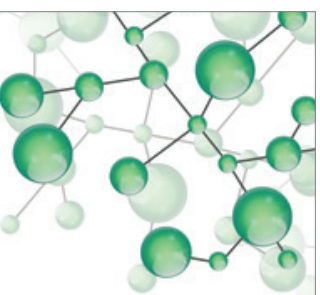

International Journal of

Inorganic Chemistry

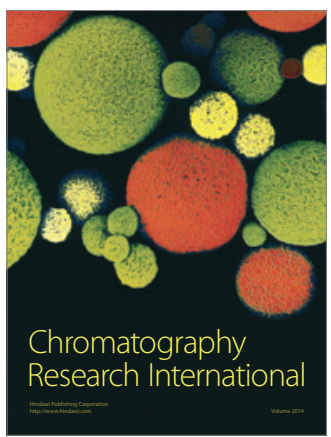

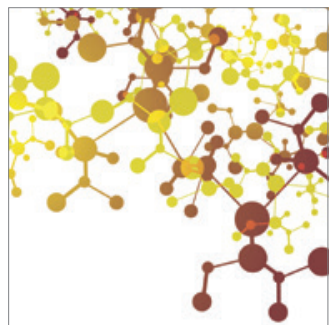

Applied Chemistry
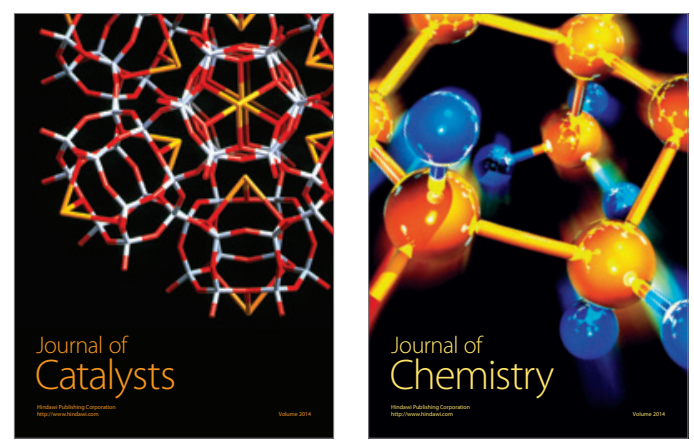
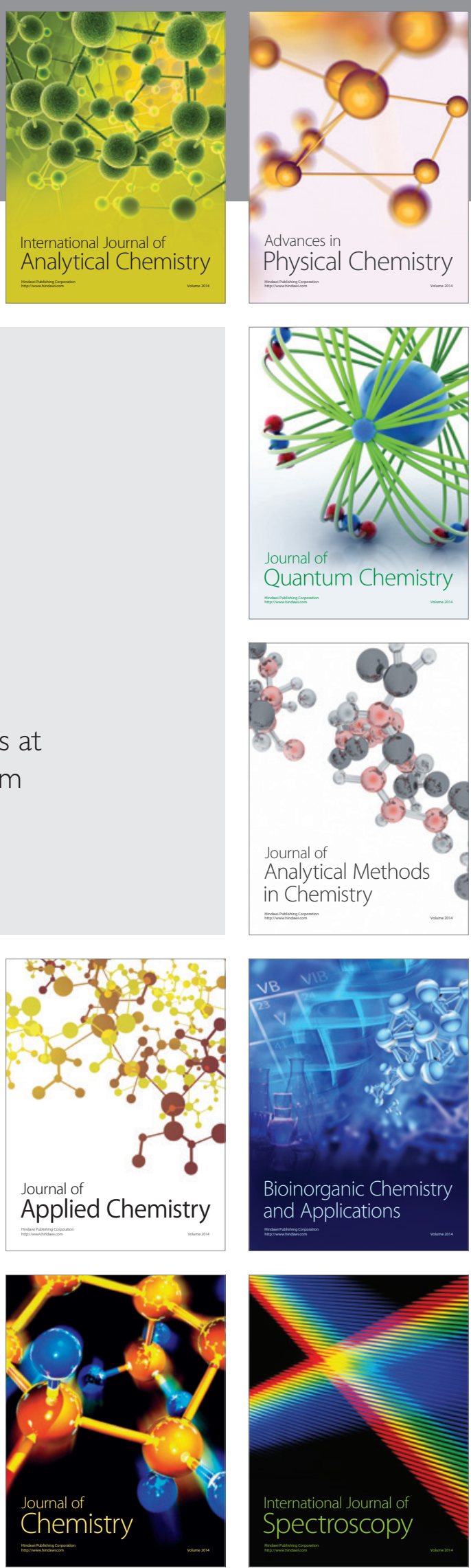